\title{
THE PROBABILITY OF PARENTAGE EXCLUSION BASED ON RESTRICTION FRAGMENT LENGTH POLYMORPHISMS
}

\author{
Hiroko Ito, Norikazu Yasuda, ${ }^{1}$ and Hideo Matsumoto ${ }^{2}$ \\ 'Division of Genetics, National Institute of Radiological Sciences, \\ Chiba 260, Japan \\ ${ }^{2}$ Department of Legal Medicine, Osaka Medical College, \\ Takatsuki 569, Japan
}

\begin{abstract}
Summary Based on restriction fragment length polymorphisms (RFLPs) reported in the Eighth International Workshop of Human Gene Mapping (HGM8) held in Helsinki, the probability of parentage exclusion was calculated and the result was compared with those currently obtained from blood groups, serum groups and biochemical markers among Japanese. RFLPs would be very promissing in use of forensic medicine as well as mutation study. The eight probes with the highest probability yielded a joint probability of parentage exclusion as $99.5 \%$. Sex-linked RFLPs, especially DXY segments which share homologous regions in both X and $Y$ chromosome, would be very efficient in paternity exclusion, while RFLPs on mitochondrial DNA would be effective in maternity exclusion in mutation study. Conventional formulae for autosomal as well as sex-linked gene and RFLPs on mitochondrial DNA were summarized.
\end{abstract}

\section{INTRODUCTION}

The information regarding red cell groups, serum groups and biochemical markers such as isozymes and haptoglobins provides the prospect of solving virtually every forensic problem of disputed parentage (Chakraborty et al., 1974). Polymorphisms in HLA-leucocyte types (Baur et al., 1984) and salivary proteins and/or isozymes (Ikemoto et al., 1977) are also of use. Recent advents of recombinant DNA techniques have added another promising marker, that is, restriction fragment length polymorphisms (RFLPs) which have been proved to be polymorphic enough for mapping genetic linkage in man (Botstein et al., 1980). A special feature of RFLPs as genetic marker is in a direct access of genetic makeup, not necessary to recognize the corresponding phenotype. RFLPs are thus inherited as a codominant fashion.

In this communication, the expected probabilities of parentage exclusion based 
on a report of the Eighth International Workshops of Human Gene Mapping (HGM8) held in Helsinki are presented to illustrate how effective RFLPs are in disputed case of parentage.

\section{MATERIALS AND METHODS}

In HGM8, Willard et al. (1985) have reported polymorphic DNA loci with allelic frequency listed as follows: 413 on autosome, 97 on an $X$ chromosome, 7 on homologous regions of $\mathrm{X}$ and $\mathrm{Y}$ chromosomes, 2 on a $\mathrm{Y}$ chromosome, 4 from ribosomal DNA, 20 from chromosomes unassigned and 8 from mitochondrial DNA. Probes not from autosomal DNA offer new aspects in disputed case of parentage. Segments from mitochondrial DNA contribute only maternity testing, while clones from $\mathrm{Y}$ chromosome are effectively useful in paternity testing irrespective of the maternal contribution. Probes which share homologous regions in both $\mathrm{X}$ and $\mathrm{Y}$ chromosomes would be highly efficient.

Sources of DNA clone were principally from Caucasoid even so few from Nigroid and/or Mongoloid. The nomenclature of DNA probe or gene was followed by Willard et al. (loc. cit.). After calculating the probability of exclusion, clones were ranked in the order of magnitude of the probability.

In calculation of the probability of parentage exclusion the highest frequency of allele at each locus was, if necessary, adjusted, the sum of allelic frequencies being 1.0. For every locus the probability of parentage exclusion was calculated by formulae developed in the next paragraph. The effect of linkage disequilibrium between tightly linked loci will be considered elsewhere.

\section{FORMULAE}

Assuming random mating at a locus with $m$ multiple alleles $A_{1}, \ldots, A_{m}$ whose respective frequency is $p_{i}, \ldots, p_{m}$, either $A_{i}$ or $A_{j}(i \neq j)$ paternal gene is excluded when the genotype of both mother and child is $A_{1} A_{j}$. Such a pair can be found in the population by the frequency $p_{i} p_{j}\left(p_{i}+p_{j}\right)$ and the chance of excluding putative father will be $\left(1-p_{i}-p_{j}\right)^{d}$, where $d=2$ for autosome and $d=1$ for $X$-linked locus. There are four additional types of mother-child combination in which the paternal gene $A_{1}$ is excluded by the probability $\left(1-p_{1}\right)^{d}$ (Table 1$)$.

The probability of parentage exclusion at the autosomal locus will be

$$
\operatorname{PA}(m)=\sum_{i<j} p_{i} p_{j}\left(p_{i}+p_{j}\right)\left(1-p_{i}-p_{j}\right)^{2}+\sum_{i=1}^{m} p_{i}\left(1-p_{i}\right)^{2}\left(1-p_{i}+p_{i}^{2}\right) .
$$

The equivalent formula was first derived by Komatsu (1952) and followed by alternative formulations (Hanset, 1975; Selvin, 1980; Ohno et al., 1982; Garber and Morris, 1983; Chakravarti and Li, 1983).

For sex-linked locus, the probability that parentage can be excluded for a 
Table 1. Mother-child ${ }^{a}$ combination, the proportion and the probability of parentage exclusion in the codominant system.

\begin{tabular}{|c|c|c|c|}
\hline $\begin{array}{l}\text { Mother-child } \\
\text { phenotype }\end{array}$ & Proportion & $\begin{array}{l}\text { Probability } \\
\text { of exclusion }\end{array}$ & $\begin{array}{l}\text { Excluded } \\
\text { allele(s) }\end{array}$ \\
\hline$A_{i} A_{j}-A_{i} A_{j}$ & $\mathrm{p}_{\mathrm{i}} \mathrm{p}_{\mathrm{j}}\left(\mathrm{p}_{\mathrm{i}}+\mathrm{p}_{\mathrm{j}}\right)$ & $\left(1-p_{i}-p_{j}\right)^{d}$ & $A_{i}$ or $A_{j}$ \\
\hline$A_{i} A_{i}-A_{i} A_{i}$ & $\mathrm{pi}^{3}$ & & \\
\hline$A_{i} A_{j}-A_{i} A_{i}$ & $\mathrm{p}_{i}^{2} \mathrm{p}_{j}$ & & \\
\hline$A_{j} A_{j}-A_{j} A_{i}$ & $p_{i} p_{j}^{2}$ & $\left(1-p_{1}\right)^{d}$ & $A_{i}$ \\
\hline$A_{k} A_{j}-A_{j} A_{i}$ & $p_{i} p_{j} p_{k}$ & & \\
\hline Others & 0 & - & - \\
\hline
\end{tabular}

a Child is daughter for X-linked polymorphisms. Either sex is possible for autosomal markers. $d=1$ for $X$-linked and $d=2$ for autosome. $p_{i}=$ frequency of allele $A_{i} . \quad$ It is understood that $i, j$ and $\mathrm{k}$ are mutually different.

random mother-child pair and a random alleged father can be calculated under two assumptions: (1) half the children are of each sex, and (2) equilibrium genotype frequencies under random mating have been reached in the population. The probability of parentage exclusion then will be

$$
\operatorname{PS}(\mathrm{m})=\frac{1}{2} \mathrm{PM}(\mathrm{m})+\frac{1}{2} \mathrm{PF}(\mathrm{m})
$$

where $\mathrm{PM}(\mathrm{m})$ is the probability of parentage exclusion when the child was son. and $\mathrm{PF}(\mathrm{m})$ is the corresponding probability if the child was daughter.

The probability of parentage exclusion at an X-linked locus becomes

$$
\operatorname{PS}_{\mathbf{x}}(m)=\frac{1}{2} \sum_{j<j} p_{i} p_{j}\left(p_{i}+p_{j}\right)\left(1-p_{i}-p_{j}\right)+\frac{1}{2} \sum_{i=1}^{m} p_{j}\left(1-p_{i}\right)\left(1-p_{i}+p_{i}^{2}\right) \text {. }
$$

Because son's Y chromosome could come from 'any male' so that $\mathrm{PM}(\mathrm{m})=0$, and only one dosage of paternal gene is relevant $(\mathrm{d}=1$ in Table 1). In case of two alleles or $\mathrm{m}=2$, we have $\mathrm{PA}(2)=\operatorname{PS}_{\mathbf{x}}(2)=\mathrm{p}_{1} \mathrm{p}_{2}\left(1-\mathrm{p}_{1} \mathrm{p}_{2}\right)$ as first noted by Bucher and Elston (1975).

For the marker on $\mathrm{Y}$ chromosome, parentage exclusion can be detected for son irrespective of maternal contributions. Thus, $P F(m)=0$ and $P M(m)=$ $\sum_{i=1}^{m} p_{i}\left(1-p_{i}\right)=1-\sum_{i=1}^{m} p_{i}^{2}($ Chakraborty, 1985) which will yield

$$
\operatorname{PS}_{\bar{y}}(\mathrm{~m})=\frac{1}{2}\left(1-\sum_{i=1}^{\mathrm{m}} \mathrm{p}_{\mathrm{i}}^{2}\right)
$$

For $\mathrm{m}=2, \mathrm{PS}_{\mathrm{y}}(2)=\mathrm{p}_{1} \mathrm{p}_{2}$ is larger than $\mathrm{PS}_{\mathrm{x}}(2)$ and $\mathrm{PA}(2)$ as mentioned by Chakraborty (loc. cit.).

DXY segments which share homologous regions in both $\mathrm{X}$ and $\mathrm{Y}$ chromosomes 
Table 2. The probability of parentage exclusion based on RFLPs.

\begin{tabular}{|c|c|c|c|c|c|c|c|}
\hline Rank & Gene-locus & $\mathrm{m}$ & $\mathrm{P}$ & Rank & Gene-locus & $\mathrm{m}$ & $\mathbf{P}$ \\
\hline \multicolumn{4}{|c|}{ Chromosome 1 (13 probes) } & \multicolumn{4}{|c|}{ Chromosome 12 (18 probes) } \\
\hline 1 & DNF15S1-A & 4 & 47.2 & 1 & $\mathrm{D} 12 \mathrm{~S} 7-\mathrm{H}$ & 4 & 29.6 \\
\hline 2 & AT3-A & 2 & 18.8 & 2 & PAH-C & 3 & 21.8 \\
\hline 3 & AMY2-B & 2 & 18.6 & 3 & D12S6-D & 2 & 18.7 \\
\hline 4 & REN-B & 2 & 18.0 & 4 & PAH-A & 2 & 18.6 \\
\hline 5 & DNF10-A & 2 & 16. 1 & 5 & COL2A'-A & 2 & 18.1 \\
\hline \multicolumn{4}{|c|}{ Chromosome 2 (21 probes) } & \multicolumn{4}{|c|}{ Chromosome 13 (19 probes) } \\
\hline 1 & D2S3-G & 4 & 46.8 & 1 & D13S3-A & 2 & 18.7 \\
\hline 2 & $\mathrm{D} 2 \mathrm{~S} 3-\mathrm{C}$ & 4 & 34.4 & 2 & D13S3-B & 2 & 18.6 \\
\hline 3 & D2S6-A & 2 & 18.8 & 3 & D13S4-A & 2 & 18.6 \\
\hline 4 & APOB-A & 2 & 18.7 & 4 & D13S15-A & 2 & 18.6 \\
\hline 5 & CRYG-B & 2 & 18.5 & 5 & D13S2-A & 2 & 18.4 \\
\hline \multicolumn{4}{|c|}{ Chromosome 3 (15 probes) } & \multicolumn{4}{|c|}{ Chromosome 14 (29 probes) } \\
\hline 1 & DNF15S2-A & 2 & 18.2 & 1 & $\mathrm{D} 14 \mathrm{~S} 4-\mathrm{C}$ & 5 & 42.6 \\
\hline 2 & D3S5-B & 2 & 17.9 & 2 & PI-G & 3 & 31.5 \\
\hline 3 & PCCB-A & 2 & 17.9 & 3 & IGHC-A & 5 & 30.2 \\
\hline 4 & D3S5-D & 2 & 17.2 & 4 & IGHC-E & 4 & 22.5 \\
\hline 5 & D3S5-C & 2 & 16.8 & 5 & IGHG-A & 2 & 18.8 \\
\hline \multicolumn{4}{|c|}{ Chromosome 4 (76 probes) } & \multicolumn{4}{|c|}{ Chromosome 15 ( 5 probes) } \\
\hline 1 & D4S24-A & 3 & 30.7 & 1 & D15S1-A & 2 & 18.7 \\
\hline 2 & D4S19-A & 2 & 18.8 & 2 & D15S3-A & 2 & 18.4 \\
\hline 3 & D4S28-A & 2 & 18.8 & 3 & D15S2-A & 2 & 16.6 \\
\hline 4 & MT2P1-A & 2 & 18.8 & 4 & D15S4-A & 2 & 10.0 \\
\hline 5 & $\mathrm{ADH} 3-\mathrm{A}$ & 2 & 18.8 & 5 & D15S4-B & 2 & 6.8 \\
\hline \multicolumn{4}{|c|}{ Chromosome 5 ( 8 probes) } & \multicolumn{4}{|c|}{ Chromosome 16 (7 probes) } \\
\hline 1 & D5S4-A & 2 & 16.1 & 1 & HBA-A & 2 & 18.8 \\
\hline 2 & D5S3-A & 2 & 14.9 & 2 & HP-A & 2 & 18.7 \\
\hline 3 & HPRTP-A & 2 & 13.4 & 3 & HP-B & 2 & 16.4 \\
\hline 4 & FMS-A & 2 & 10.6 & 4 & APRT-A & 2 & 13.8 \\
\hline 5 & D5S1-A & 2 & 8.2 & 5 & APRT-B & 2 & 13.4 \\
\hline \multicolumn{4}{|c|}{ Chromosome 6 ( 26 probes) } & \multicolumn{4}{|c|}{ Chromosome 17 (15 probes) } \\
\hline 1 & D6S2-B & 3 & 30.6 & 1 & D17S2-A & 7 & 52.4 \\
\hline 2 & D6S10-A & 3 & 24.0 & 2 & D17S2-B & 4 & 29.4 \\
\hline 3 & D6S7-A & 4 & 23.2 & 3 & MYH2-B & 3 & 24.5 \\
\hline 4 & D6Z1-C & 2 & 18.7 & 4 & GH2-B & 2 & 18.8 \\
\hline 5 & $\mathrm{D} 6 \mathrm{Z1-G}$ & 2 & 18.7 & 5 & D17Z1-B & 2 & 18.7 \\
\hline \multicolumn{4}{|c|}{ Chromosome 7 (17 probes) } & \multicolumn{4}{|c|}{ Chromosome 18 ( 5 probes) } \\
\hline 1 & D7S10-A & 3 & 20.3 & 1 & DHFRP-A & 2 & 18.8 \\
\hline 2 & COL1A2-A & 2 & 18.0 & 2 & D18S3-C & 2 & 18.4 \\
\hline 3 & TCRB-B & 2 & 17.7 & 3 & D18S3-B & 2 & 18.4 \\
\hline 4 & D7S8-A & 2 & 17.0 & 4 & D18S1-A & 2 & 15.5 \\
\hline 5 & D7S11-A & 2 & 16.6 & 5 & D18S3-A & 2 & 6.8 \\
\hline \multicolumn{4}{|c|}{ Chromosome 8 ( 6 probes) } & \multicolumn{4}{|c|}{ Chromosome 19 (16 probes) } \\
\hline 1 & PLAT-A & 2 & 18.8 & 1 & D19S11-D & 3 & 20.5 \\
\hline 2 & CA2-A & 2 & 18.8 & 2 & $\mathrm{APOC} 2-\mathrm{B}$ & 2 & 18.7 \\
\hline 3 & TG-A & 2 & 13.4 & 3 & $\mathrm{APOC} 2-\mathrm{A}$ & 2 & 18.6 \\
\hline 4 & TG-B & 2 & 11.1 & 4 & D19S11-E & 2 & 18.6 \\
\hline 5 & MOS-A & 2 & 2.8 & 5 & D19S6-A & 2 & 18.2 \\
\hline
\end{tabular}


Table 2. (Continued)

\begin{tabular}{|c|c|c|c|c|c|c|c|}
\hline Rank & Genelocus & $\mathrm{m}$ & $P$ & Rank & Genelocus & $\mathrm{m}$ & $\mathrm{P}$ \\
\hline \multicolumn{4}{|c|}{ Chromosome 9 (16 probes) } & \multicolumn{4}{|c|}{ Chromosome 20 (4 probes) } \\
\hline 1 & D9S1-A & 2 & 18.7 & 1 & $\mathrm{D} 20 \mathrm{~S} 6-\mathrm{A}$ & 2 & 18.7 \\
\hline 2 & INFA-A & 2 & 18.6 & 2 & $\mathrm{D} 20 \mathrm{~S} 4-\mathrm{A}$ & 2 & 18.1 \\
\hline 3 & D9S4-A & 2 & 17.9 & 3 & D20S5-A & 2 & 17.2 \\
\hline 4 & ASSP3-A & 2 & 16.6 & 4 & $\mathrm{D} 20 \mathrm{~S} 5-\mathrm{B}$ & 2 & 16.8 \\
\hline 5 & D9S3-A & 2 & 16.1 & \multicolumn{4}{|c|}{ Chromosome 21 (43 probes) } \\
\hline 6 & D9S3-B & 2 & 16. 1 & 1 & D21S55-A & 4 & 37.8 \\
\hline \multicolumn{4}{|c|}{ Chromosome 10 (3 probes) } & 2 & D21S26-B & 3 & 34.4 \\
\hline 1 & D10S3-A & 2 & 18.7 & 3 & D21S11-A & 3 & 20.9 \\
\hline 2 & $\mathrm{UK}-\mathrm{A}$ & 2 & 16.6 & 4 & D21S8-A & 2 & 18.8 \\
\hline 3 & D10S1-A & 2 & 11.1 & 5 & D21S56-A & 2 & 18.8 \\
\hline \multicolumn{4}{|c|}{ Chromosome 11 (35 probes) } & \multicolumn{4}{|c|}{ Chromosome 22 (16 probes) } \\
\hline 1 & INS-A & 6 & 62.3 & 1 & IGLV-D & 3 & 33.4 \\
\hline 2 & D11S16-A & 3 & 33.0 & 2 & IGLV-A & 3 & 30.0 \\
\hline 3 & HRAS1-B & 7 & 30.0 & 3 & IGLC-A & 4 & 20.0 \\
\hline 4 & D11S19-A & 2 & 18.8 & 4 & IGLV-B & 2 & 18.4 \\
\hline 5 & INS-D & 2 & 18.8 & 5 & MB-A & 2 & 18.0 \\
\hline 6 & CAT-A & 2 & 18.8 & & & & \\
\hline \multicolumn{4}{|c|}{ Unassigned ( 20 probes) } & \multicolumn{4}{|c|}{ Pseudoautosomal (7 probes) } \\
\hline 1 & $\mathrm{~m} 33.6-\mathrm{A}$ & 8 & 54.2 & 1 & DXYS1-A & $\stackrel{2}{\left(18.2^{\circ}\right.}$ & $\begin{array}{l}42.2 \\
\left.+24.0^{b}\right)\end{array}$ \\
\hline 2 & $\mathrm{~m} 33.4-\mathrm{A}$ & 5 & 42.1 & 2 & DXYS1-B & $\begin{array}{l}2 \\
(18.2\end{array}$ & $\begin{array}{r}42.2 \\
+24.0)\end{array}$ \\
\hline 3 & $\mathrm{~m} 33.1-\mathrm{A}$ & 6 & 30.3 & 3 & DXYS17-B & $\stackrel{2}{(16 .}$ & $\begin{array}{l}37.6 \\
+21.0)\end{array}$ \\
\hline 4 & $\mathrm{~m} 33.15-\mathrm{A}$ & 2 & 18.8 & 4 & DXYS12-A & $\stackrel{2}{2}$ & $\begin{array}{c}32.3 \\
+17.7)\end{array}$ \\
\hline 5 & fD12S3-A & 2 & 18.8 & 5 & DXYS2-A & $\stackrel{2}{213.8}$ & $\begin{array}{r}30.4 \\
+16.6)\end{array}$ \\
\hline \multicolumn{4}{|c|}{$\mathrm{X}$ chromosome ( 97 probes) } & 6 & DXYS13-B & 2 & $\begin{array}{l}15.7 \\
+8.2)\end{array}$ \\
\hline 1 & DXS52-A & 8 & 37.9 & 7 & DXYS13-A & 2 & $\begin{array}{l}15.7 \\
+\quad 8.2)\end{array}$ \\
\hline 2 & DNF1-A & 4 & 30.5 & \multicolumn{4}{|c|}{ Mitochondrial (8 probes) } \\
\hline 3 & DXS92-A & 3 & 24.6 & 1 & mtDNA-A & 6 & 55.7 \\
\hline 4 & DXS51-A & 2 & 18.8 & 2 & mtDNA-B & 7 & 26.9 \\
\hline 5 & DXS92-B & 2 & 18.8 & 3 & $\mathrm{mtDNA}-\mathrm{C}$ & 5 & 21.9 \\
\hline 6 & DXS103-A & 2 & 18.8 & 4 & mtDNA-D & 2 & 9.5 \\
\hline 7 & DXS144-A & 2 & 18.8 & 5 & mtDNA-E & 3 & 7.7 \\
\hline 8 & DXZ1-B & 2 & 18.8 & 6 & mtDNA-F & 3 & 5.9 \\
\hline 9 & DXZ1-E & 2 & 18.8 & 7 & mtDNA-G & 3 & 5.9 \\
\hline 10 & $\mathrm{DXZ1-F}$ & 2 & 18.8 & 8 & mtDNA-H & 2 & 3.9 \\
\hline \multicolumn{4}{|c|}{ Y chromosome ( 2 probes) } & \multicolumn{4}{|c|}{ Ribosomal (4 probes) } \\
\hline 1 & DYS11-A & 2 & 21.0 & 1 & rDNA-C & 4 & 33.5 \\
\hline \multirow[t]{3}{*}{2} & DYS11-B & 2 & 21.0 & 2 & rDNA- $A^{\prime}$ & 3 & 29.3 \\
\hline & & & & 3 & rDNA-B & 2 & 16.6 \\
\hline & & & & 4 & rDNA-A & 2 & 13.4 \\
\hline
\end{tabular}

a. $\mathrm{PF}(\mathrm{m}) / 2$, $\mathrm{PM}(\mathrm{m}) / 2$. $\mathrm{m}$, number of allele; $\mathrm{P}$, probability of exclusion. 
will be more efficient. The probability of parentage exclusion will be the sum of formulae (3) and (4), provided that sex of child is known. Namely, we have

$$
\mathrm{PS}_{\mathrm{xy}}(\mathrm{m})=\mathrm{PS}_{\mathrm{x}}(\mathrm{m})+\mathrm{PS}_{\mathrm{y}}(\mathrm{m})
$$

so that $\operatorname{PS}_{x y}(2)=p_{1} p_{2}\left(2-p_{1} p_{2}\right)$ which is larger than either $\operatorname{PS}_{y}(2)$ or $\operatorname{PS}_{x}(2)$ or $\operatorname{PA}(2)$. In general, this statement for sex-linked marker can be said for arbitrary number of allele, provided that allelic frequencies are equal at every locus:

$$
\operatorname{PS}_{x y}(m)>\operatorname{PS}_{y}(m)>\operatorname{PS}_{x}(m)
$$

The probability of maternity exclusion for genes from mitochondrial DNA co sld be obtained from $2 \mathrm{PS}_{\bar{y}}(\mathrm{~m})$ since paternal contrib tions to child (either sex) were irrelevant (Giles et al., 1980).

For probes not assigned chromosome, the probability of parentage exclusion was calculated by assuming that they were on autosome.

\section{RESULTS}

Table 2 summarizes the probability of parentage exclusion based on RFLPs. For probes form assigned and/or unassigned autosome, only the five probes with the highest probability of parentage exclusion are presented in order to avoid the voluminous table. A complete list would be available upon request to author. All are listed for the other probes. Gene or probe name as well as polymorphic locus name was taken after workshop symbol and joined as DNF15S1-A where DNF15S1 and A stood for gene and locus name, respectively. As expected, it is observed that the more the number of allele is the higher the probability of parentage exclusion

Table 3. Ranking of the ten DNA segments which gave the higher magnitude of the probability

\begin{tabular}{|c|c|c|c|c|c|c|}
\hline Rank & $\begin{array}{l}\text { Chromosome } \\
\text { region }\end{array}$ & $\begin{array}{c}\text { Gene/probe } \\
\text { name }\end{array}$ & Locus & $\begin{array}{l}\text { No. of } \\
\text { allele }\end{array}$ & $P$ & $\mathrm{CP}$ \\
\hline 1 & $11 \mathrm{p} 15$ & INS & A & 6 & 62.3 & 62.3 \\
\hline 2 & Unassigned & $\mathrm{m} 33.6$ & A & 8 & 54.2 & 82.7 \\
\hline 3 & 17 & $\mathrm{D} 17 \mathrm{~S} 2$ & A & 7 & 52.4 & 91.8 \\
\hline 4 & $1 \mathrm{p} 36$ & DNF15S1 & A & 4 & 47.2 & 95.7 \\
\hline 5 & $2 q 35-37$ & D2S3 & $\mathrm{G}$ & 4 & 46.8 & 97.7 \\
\hline 6 & 14 & D14S4 & $\mathrm{C}$ & 5 & 42.6 & 98.7 \\
\hline 7 & Unassigned & $\mathrm{m} 33.4$ & A & 5 & 42.1 & 99.2 \\
\hline 8 & $2 \operatorname{lq} 22.3$ & D21S55 & A & 4 & 37.8 & 99.5 \\
\hline 9 & $2 q 35-37$ & D2S3 & $\mathrm{C}$ & 4 & 34.4 & $-^{\mathrm{a}}$ \\
\hline 10 & 21 pter-q22.2 & D21S26 & $\mathbf{B}$ & 3 & 34.4 & $-b$ \\
\hline
\end{tabular}
of parentage exclusion in autosome and unassigned regions.

$\mathrm{P}$, probability of exclusion at each polymorphism; CP, cumulative probability of exclusion when linkage disequilibrium did not exist among loci taken into account. " Suspected linkage disequilibrium between D2S3-A and $-C$ and that between D21S55-A and D21S26-B. 
yielded. In Table 3 the ten probes with the highest probability of parentage exclusion among autosomes and/or unassigned chromosomes are ranked in the order of magnitude in the probability. INS-A is highest (62.3\%), followed by m33.6-A $(54.2 \%)$ and D17S2-A $(52.4 \%)$. Incidentally, eight genes of the highest ranks seem to happen from different chromosomes, thus the combined probability of parentage exclusion can be calculated as $99.5 \%$ without bothering the effect of linkage disequilibrium.

Five of seven DXY segments yielded more than $30 \%$ of the probability of parentage exclusion, even when only two alleles were observed. DXY segments could be very promissing marker in disputed case of parentage. Two Y-segments both yielded $21 \%$ of the probability of paternity exclusion.

\section{DISCUSSION}

Many conventional genetic systems do not give more than $30 \%$ probability of parentage exclusion among Japanese. The highest values have been found in HLA system; $57.5 \%$ in HLA-A, $80.9 \%$ in HLA-B, $42.6 \%$ in HLA-C, $69.7 \%$ in HLA-DR and $29.5 \%$ in HLA-DQ, which were calculated from allelic frequencies reported in the Ninth International Histocompatibility Workshop (Baur et al., 1984). The next ones would be Gm system with $40.7 \%$ and $\mathrm{Gc}$ system with $38.2 \%$. Common polymorphisms, $\mathrm{PGM}_{1}, \mathrm{Rh}, \mathrm{MNSs}$ and $\mathrm{ABO}$ then follow with the respective figure as $26.4 \%, 23.7 \%, 23.5 \%$ and $19.2 \%$ (Matsumoto, 1976). By no means, these figures could not be compared directly with the ones in Tables 2 and 3 because of possibly racial difference in allelic frequency of RFLPs, as described in $\beta$-globin cluster on human chromosome 11 (Antonarakis et al., 1982). However, it is obvious that use of RFLPs is very fruitful in forensic medicine. In this regard, study of RFLPs among Japanese population is highly demanded. Only one study for mitochondrial DNA RFLPs among Japanese was cited in HGM8 (mtDNA-C with 22\%) (Horai et al., 1984).

We have so far assumed RFLPs to be inherited as Mendelian codominant, since RFLPs are the result of single-base pair changes, deletion, addition and other local rearrangements. RFLPs could, however, be due to the activity of DNA modifying enzyme (Bird, 1978). In such case mode of inheritance will be expressed as either dominants or recessives. Accordingly, the formulae developed in this paper could not always be applied. An intriguing possibility is that RFLPs are a recessive allele, as an ABO-like system where there are m-1 codominant alleles and one silent gene. The probability of parentage exclusion can be calculated from

$$
\begin{aligned}
P(m)= & \sum_{i<j}^{m-1} p_{i} p_{j}\left(p_{i}+p_{j}\right)\left(1-p_{i}-p_{j}\right)^{2}+\sum_{i=1}^{m-1} p_{i}\left(1-p_{i}\right)^{4} \\
& +\sum_{i=1}^{m-1} p_{i}\left(p_{i}+r+r p_{i}\right)\left[\left(1-p_{i}-r\right)^{2}+p_{i}^{2}-H\right]+r^{2}\left[(1-r)^{2}-H\right],
\end{aligned}
$$


in which $H=\sum_{i=1}^{m-1} p_{i}^{2}$ and $r$ is the frequency of silent gene. The equivalent formula has been applied to HLA polymorphisms (Chakravarti and Li, 1983). A complication here will be found that the probability of exclusion $\mathrm{P}(\mathrm{m})$ dose not converge to the corresponding probability in the m-1 multiple allele codominant system, PA(m-1) (formula (1)), when the frequency of silent allele approaches to zero. The limiting difference $\sum_{i=1}^{m-1} p_{i}^{4}-\left(\sum_{i=1}^{m-1} p_{i}^{2}\right)^{2}$ due to the presence of the silent allele remains even when the frequency of the recessive gene is extremely rare. The fact had first been mentioned by Komatsu (1952) for $\mathrm{m}=2$ in a comparison of the probabilities in $\mathrm{ABO}$ and $\mathrm{MN}$ blood groups.

Acknowledgement We are indebted to Dr. Masa-aki Hori who kindly made it available the material of HGM8.

\section{REFERENCES}

Antonarakis, S.E., Boehn, C.D., Giardina, P.J.V., and Kazazian, H.H., Jr. 1982. Nonrandom association of polymorphic restriction sites in the $\beta$-globin gene cluster. Proc. Natl. Acad. Sci. U.S.A. 79: 137-141.

Baur, M.P., Neugebauer, M., Deppe, H., Sigmund, M., Luton, T., Mayer, W.K., and Albert, E.D. 1984. Population analysis on the basis of deduced haplotypes from random families. In Histocompatibility Testing 1984, Albert, E.D., Baur, M.D., and Mayer, W.K., eds., SpringerVerlag, Berlin, pp. 333-341.

Bird, A.P. 1978. Use of restriction enzymes to study eukaryotic DNA methylation. II. The symmetry of methylated sites supports semi-conservative copying of the methylation pattern. J. Mol. Biol. 118: 49-60.

Botstein, D., White, R.L., Skolnick, M., and Davis, R.W. 1980. Construction of a genetic linkage map in man using restriction fragment length polymorphisms. Am. J. Hum. Genet. 32: 314-333.

Bucher, K.D. and Elston, R.C. 1975. Estimation of nonpaternity for X-linked trait. $A m . J . H u m$. Genet. 27: 689-690.

Chakraborty, R. 1985. Paternity testing with genetic markers: Are Y-linked genes more efficient than autosomal ones? Am. J. Med. Genet. 21: 297-305.

Chakraborty, R., Shaw, M., and Schull, W.J. 1974. Exclusion of paternity: the current state of the art. Am. J. Hum. Genet, 26: 477-488.

Chakravarti, A. and Li, C.C. 1983. The effect of linkage on paternity calculations. In Inclusion Probabilities in Parentage Testing, Walker, R.H., ed., American Association of Blood Banks, Arlington, pp. 411-422.

Gaber, R.A. and Morris, J.W. 1983. General equations for the average power of exclusion for genetic systems of $\mathrm{n}$ codominant alleles in one-parent and non-parent cases of disputed parentage. In Inclusion Probabilities in Parentage Testing, Walker, R.H., ed., American Association of Blood Banks, Arlington, pp. 277-280.

Gilles, R.E., Blanc, H., Cann, H.M., and Wallace, D.C. 1980. Maternal Inheritance of human mitocondrial DNA. Proc. Natl. Acad. Sci. U.S.A. 77: 6715-6719.

Hanset, R. 1975. Probabilite d'exclusion de paterrite et de monozygotie, probabilite de sinilitude. Generalisation a N alleles co-dominants. Ann. Med. Vet. 119:71-81.

Horai, S., Gojobori, T., and Matsunaga, E. 1984. Mitochondrial DNA polymorphism in Japan. I. Analysis with restriction enzymes of six base pair recognition. Hum. Genet. 68: 324-332. 
Ikemoto, S., Minaguchi, K., and Hinohara, H. 1977. Genetic polymorphisms of human parotide salivary proteins ( $\mathrm{Pa}, \mathrm{Pb}, \mathrm{Pr}, \mathrm{Db}$ and $\mathrm{Dm}$ ) and salivary amylase isozyme in Japanese population. Hum. Hered. 27 : 328-331.

Komatsu, Y. 1952. Probabilistic-theoretic investigations on inheritance. VII. Non-paternity problems. Proc. Japan Acad. 28: 102-125.

Matsumoto, H. 1976. Knowledge of Blood Groups, Kanehara-shoten, Tokyo (in Japanese), p. 132.

Ohno, Y., Sebetan, I., and Akaishi, S. 1982. A simple method for calculating the probability of excluding paternity with any number of codominant alleles. Forensic Sci. Int. 19: 93-98.

Selvin, S. 1980. Probability of nonpaternity determined by multiple allele codominant systems. Am. J. Hum. Genet. 32: 276-278.

Willard, H.F., Skolnick, M.H., Person, P.L., and Mandel, J.-L. 1985. Human gene mapping by recombinant DNA techniques. Table 4. Polymorphic DNA segments. Cytogenet. Cell Genet. 40: $360-489$. 